Illinois State University

ISU ReD: Research and eData

Theses and Dissertations

7-8-2019

\title{
Connecting the dots: exploring the relationship between avian eggshell pigmentation and paternal provisioning effort
}

Kara E. Hodges

Illinois State University, kehodg1@ilstu.edu

Follow this and additional works at: https://ir.library.illinoisstate.edu/etd

Part of the Biology Commons, and the Ecology and Evolutionary Biology Commons

\section{Recommended Citation}

Hodges, Kara E., "Connecting the dots: exploring the relationship between avian eggshell pigmentation and paternal provisioning effort" (2019). Theses and Dissertations. 1157.

https://ir.library.illinoisstate.edu/etd/1157

This Thesis is brought to you for free and open access by ISU ReD: Research and eData. It has been accepted for inclusion in Theses and Dissertations by an authorized administrator of ISU ReD: Research and eData. For more information, please contact ISUReD@ilstu.edu. 
CONNECTING THE DOTS: EXPLORING THE RELATIONSHIP BETWEEN AVIAN

EGGSHELL PIGMENTATION AND PATERNAL PROVISIONING EFFORT

\section{KARA E. HODGES}

\section{Pages}

In a number of bird species, eggs laid by females breeding in the same population can vary extensively in the extent of their eggshell pigmentation, but the adaptive significance of this intraspecific variation remains unknown. One hypothesis posits that shell pigmentation is an honest signal of female quality that reflects her level of oxidative stress, one that is used by males to inform their subsequent paternal investment. We employed a reciprocal clutch crossfostering design to test whether provisioning by male house wrens (Troglodytes aedon) responds to the clutch pigmentation of their mates. In experimental replicates, dark clutches were swapped with light clutches two days into incubation, whereas in control replicates, light clutches were swapped with light clutches, or dark clutches with dark. Shortly before hatching, clutches were returned to their original nest to avoid the confounding effect of nestling quality on male provisioning effort. We found no effect of clutch pigmentation on male provisioning effort. We did find, however, that females that laid lighter clutches were significantly older than females that laid darker clutches and tended to be of greater structural body size. We also found that nestlings hatching from lighter clutches had a significantly higher size-corrected body mass at brood-day 11, a measure that is strongly predictive of survival and recruitment to the breeding population. Although it seems likely that male house wrens are fully capable of observing eggshell pigmentation and may be able to infer female quality from it, males do not use this 
information when provisioning their young. This may be because of constraints on reproductive opportunities imposed by a socially monogamous mating system, restricting the pool of potential female partners, in concert with a short average lifespan.

KEYWORDS: eggshell pigmentation, provisioning, maculation, protoporphyrin, house wren, sexual selection 
CONNECTING THE DOTS: EXPLORING THE RELATIONSHIP BETWEEN AVIAN

EGGSHELL PIGMENTATION AND PATERNAL PROVISIONING EFFORT

KARA E. HODGES

A Thesis Submitted in Partial
Fulfillment of the Requirements
for the Degree of
MASTER OF SCIENCE
School of Biological Sciences
LLINOIS STATE UNIVERSITY

2019 
Copyright 2019 Kara E. Hodges 
CONNECTING THE DOTS: EXPLORING THE RELATIONSHIP BETWEEN AVIAN

EGGSHELL PIGMENTATION AND PATERNAL PROVISIONING EFFORT

KARA E. HODGES

COMMITTEE MEMBERS:

Charles F. Thompson, Co-Chair

Scott K. Sakaluk, Co-Chair

Alysia D. Vrailas-Mortimer, Co-Chair

Ben M. Sadd

Steven A. Juliano 


\section{ACKNOWLEDGMENTS}

I would like to start by thanking my advisors, Charlie Thompson, Scott Sakaluk, and Alysia Mortimer, for their constant guidance and support throughout this process, as well as my un-official advisor, Nate Mortimer. I owe a huge heap of thanks to all wren crew members, in particular Rachael DiSciullo, Dylan Poorboy, and Beth Weber, for their contributions to data collection. In addition, I want to thank the biology department faculty and graduate students for their instruction, assistance, and comradery. I would also like to express gratitude to the ParkLands Foundation (Merwin Preserve), the Illinois Great Rivers Conference of the United Methodist Church, and the Sears and Butler families for the use of their properties. Finally, a shout-out to the wrens, who played a reluctant but essential role in my research. This work was funded by the National Institutes of Health, the American Ornithological Society, Sigma Xi Scientific Research Honor Society, and the Beta Lambda Chapter of the Phi Sigma Honor Society.

K.E.H. 


\section{CONTENTS}

Page

ACKNOWLEDGMENTS

CHAPTER I: INTRODUCTION AND METHODS 1

Introduction $\quad 1$

$\begin{array}{ll}\text { Methods } & 6\end{array}$

$\begin{array}{ll}\text { Study Site and Species } & 6\end{array}$

$\begin{array}{ll}\text { Field Procedures } & 7\end{array}$

$\begin{array}{ll}\text { Photo Processing and Machine Learning } & 10\end{array}$

$\begin{array}{ll}\text { Statistical Analyses } & 12\end{array}$

CHAPTER II: RESULTS AND DISCUSSION 14

$\begin{array}{ll}\text { Results } & 14\end{array}$

$\begin{array}{ll}\text { Effects on Paternal Provisioning } & 14\end{array}$

Effects on Within-Season Reproductive Success 14

Egg Pigmentation and Maculation in Relation to Female Size and Age $\quad 14$

Effects on Offspring 15

Effects on Adult Return Rates and Offspring Recruitment 15

$\begin{array}{ll}\text { Discussion } & 15\end{array}$

$\begin{array}{ll}\text { REFERENCES } & 21\end{array}$

APPENDIX A: TABLES AND FIGURES 


\section{CHAPTER I: INTRODUCTION AND METHODS}

\section{Introduction}

Avian eggshell colouration varies extensively among species, ranging from white to a broad spectrum of browns, blues, or greens. In addition to these base colours, eggshells may show a wide gamut of maculation (spotting) patterns and variable amounts of ultraviolet reflection (Hauber, 2014). This diversity of pigmentation has long been a source of investigation (Cherry \& Gosler, 2010; Gosler et al., 2005; Kilner, 2006) that has focused primarily on two questions: i) what are the proximate mechanisms by which eggshells derive their pigmentation? and ii) what is the adaptive significance, if any, of variation in eggshell pigmentation?

With regard to the first question, the majority of all eggshells' colouration comes from just two pigments: biliverdin and protoporphyrin IX (hereafter protoporphyrin) (Cassey et al., 2012; Gosler et al., 2005; Mikšík et al., 1996; Moreno \& Osorno, 2003; Reynolds et al., 2009). Biliverdin is responsible for blue-to-green hues, and protoporphyrin, for browns, reds, and pinks. Both pigments occur in the blood and body fluids of vertebrates because they are involved in the creation and destruction of red blood cells (Afonso et al., 1999; Casini et al., 2001; Grinstein et al., 1959; London et al., 1949; Moreno \& Osorno, 2003; Morgan et al., 1979). Protoporphyrin plays a major role as an intermediary in heme synthesis in the production of hemoglobin (Grinstein et al., 1959; London et al., 1949) and is a strong pro-oxidant, reacting with oxygen and light to generate free radicals (Afonso et al., 1999). When levels of protoporphyrin rise above the threshold needed for heme synthesis, free radicals increase (Afonso et al., 1999) and the level of oxidative stress increases (Moreno and Osorno, 2003). Excess protoporphyrin is removed by the liver for excretion via the intestines (Grinstein et al., 1959; London et al., 1949; Morgan et al., 1979). Deposition of protoporphyrin to an eggshell takes place in the shell gland 
at the end of egg formation (Board \& Sparks, 1991; Lavelin et al., 2000; Nys et al., 1999) when epithelia cells deposit pigments on the outermost layers of the shell (Board \& Sparks, 1991; Lang \& Wells, 1987; Wang et al., 2007). How the pigments arrive at the shell gland is not well understood; they may be filtered from circulating blood and fluid (Lang \& Wells, 1987), or synthesized within the shell gland itself (Samiullah et al., 2015; Zhao et al., 2006), or even some combination of both (Hargitai et al., 2017a).

Empirical work addressing the adaptive significance of inter- and intraspecific differences in eggshell pigmentation has been a long-running, ongoing effort (Lyon, 1993; Moreno \& Osorno, 2003; Reynolds et al., 2009; Tinbergen et al., 1962). Interspecifically, it is clear that in at least some open-nesting species, eggshell pigmentation camouflages eggs against egg predators (Duval et al., 2016; Weidinger, 2001), whereas in some brood-parasitized species, it makes it possible for the host to distinguish its eggs from those of the parasite (Reynolds et al., 2009; Stoddard et al., 2014). However, such explanations, as well as others, for interspecific differences in eggshell pigmentation, are unlikely to explain the widespread occurrence of significant intraspecific variation in pigmentation.

Extensive variation among clutches produced by females of the same species and, even, by females in the same population can be stark (Bischoff \& Murphy, 1993; Griffith et al., 2009; Lahti \& Lahti, 2002), as variation in protoporphyrin-based eggshell pigmentation in our study population of house wrens (Troglodytes aedon) attests (Fig. A-1). A number of hypotheses have been proposed to explain such intraspecific variation, including the possibility that i) protoporphyrin plays a structural role by acting as a shock absorber when calcium is limited (Gosler et al., 2005; Kennedy \& Vevers, 1973; Mikšík et al., 1996; Moreno \& Osorno, 2003) or that ii) protoporphyrin functions as a sexually selected signal (Moreno \& Osorno, 2003). Moreno 
and Osorno (2003) proposed that eggshell pigmentation (both biliverdin and protoporphyrin) provides an honest signal of female quality, with the amount of pigment providing an indication of the level of oxidative stress to which a laying female is subject. As oxidative stress is damaging to a number of physiological functions (Finkel \& Holbrook, 2000; Mittler, 2002; Sies, 1997), selection for the ability to withstand this stress should be strong (Dowling \& Simmons, 2009). If eggshell pigmentation can be used to discriminate between females and their resultant offspring with high and low resistance to oxidative stress, then male birds could use this information to modify their parental investment to maximize their reproductive success (Trivers, 1972; Moreno \& Osorno, 2003).

There are two competing hypotheses to explain what increased protoporphyrin-based pigmentation in eggshells reveals about the physiological condition of females. The 'goodquality' hypothesis posits that if two females have the same level of elevated protoporphyrin, the female that is able to shunt the excess to her eggshells, thereby laying more heavily pigmented eggs, will experience less oxidative stress compared with a female that cannot do so and thus lays less-pigmented eggs (De Coster et al., 2013; Hargitai et al., 2016; Moreno \& Osorno, 2003). In contrast, the 'poor-quality' hypothesis proposes that the amount of protoporphyrin that a female deposits in her eggshells reflects the amount within the female at the time of laying; thus, highly pigmented eggs are produced by females with high levels of protoporphyrin and of poorer oxidative balance, whereas eggs with less pigment are produced by females with less protoporphyrin and of superior oxidative balance (De Coster et al., 2013; Hargitai et al., 2016; Moreno \& Osorno, 2003).

Tests of these two hypotheses have produced mixed results. Evidence consistent with the good-quality hypothesis has been found in blue tits (Cyanistes caeruleus), which have 
protoporphyrin-based maculations. Pigment darkness of these maculations positively correlated with female tarsus length, and pigment-spread positively correlated with female clutch size and the tarsus length of her nestlings (Sanz \& García-Navas, 2009). Blue tit eggs with larger maculations had higher maternally-derived antibody concentrations (Holveck et al., 2012), and a follow-up study showed that higher-quality females produced more pigmented eggs and were less affected by experimentally increased reproductive costs (Holveck et al., 2019). Great tits (Parus major) also produce similarly maculated eggs, and anemic females produced less pigmented eggshells than females that were not anemic (De Coster et al., 2013). On the other hand, in a different study on blue tits, females with more maculated eggs were in poorer body condition, had higher stress-protein levels, and had lower immunoglobulin levels than females with less-maculated eggs (Martínez-de la Puente et al., 2007). Duval et al. (2013b) similarly found that the eggshells produced by female Japanese quail (Coturnix japonica) on a foodrestricted diet had more protoporphyrin than control females.

If there is a positive or negative relationship between eggshell pigmentation and female health, then it is possible that the birds themselves could be paying attention to eggshell appearance (Moreno \& Osorno, 2003; Moreno et al., 2006b). Male birds, in particular, may be selected to evaluate eggshell pigmentation and adjust their subsequent reproductive effort to maximize their own fitness (Burley, 1986; Byrne \& Rice, 2006; Edwards \& Chapman, 2011). This should be especially true for males of species in which there is biparental care in provisioning the nestlings (Burley, 1986; Edwards \& Chapman, 2011; Jones et al., 2001). Thus, the information provided by eggshell maculation could allow males to increase or decrease their reproductive effort. For example, if eggshell pigmentation signals that their mate is in good condition, males could maximize their reproductive success by increasing nestling provisioning; 
conversely, if the signal indicates that their mate is in poor condition, males may reduce their provisioning effort or even abandon their mate and seek a new mate in better condition.

Few studies have investigated the effect of eggshell colouration on paternal investment in regard to protoporphyrin pigmentation. In a double cross-fostering experiment, Stoddard et al. (2012) calculated maculation size, pattern contrast, pattern coverage, and pattern dispersion for great tit eggs and found no effect of these pigmentation measures on male provisioning (though they did find that heavier females laid paler, less-maculated eggs). Likewise, Bulla et al. (2012) found no connection between clutch maculation and male investment in the form of male incubation in Northern Lapwing (Vanellus vanellus). In house wrens, Walters and Getty (2010) found a correlation between eggshell pigmentation and female provisioning, but not male provisioning, though the design of this experiment did not account for the possibly confounding influence of nestling quality. However, Poláček et al. (2017) found that not only was clutch pigmentation positively correlated to eggshell protoporphyrin content, but also to male provisioning in tree sparrows (Passer montanus). Walters et al. (2014) found an opposite effect in house wrens, with males increasing their provisioning of nestlings in nests to which the authors had earlier added an artificially light egg. With results of studies on the effect of eggshell protoporphyrin pigmentation on male provisioning limited and conflicting, there is clearly a pressing need for further investigation.

In this study we aimed to investigate the role played by protoporphyrin pigmentation in the eggshells of house wrens. We tested the hypothesis that males adjust their parental investment, viz., nestling provisioning effort, based on the degree of egg pigmentation. If the good-quality hypothesis is true, we predicted that nestlings hatching from clutches with morepigmented eggs (i.e. darker, more spotted) would receive greater paternal provisioning than 
nestlings hatching from lighter clutches. If, however, the poor-quality hypothesis is correct, we predicted that nestlings hatching from clutches with less-pigmented eggs (i.e. lighter, less spotted) would receive greater paternal provisioning than those hatching from darker clutches.

\section{Methods}

\section{Study Site and Species}

The experiment took place on the Mackinaw study area in McLean County, Illinois $\left(40.665^{\circ} \mathrm{N}, 88.89^{\circ} \mathrm{W}\right)$. This 130 -ha site has 700 nestboxes spaced $30-\mathrm{m}$ apart in north-south rows $60 \mathrm{~m}$ apart, 5.4 boxes/ha. Each box is mounted on a $1.5-\mathrm{m}$ metal pole above a $43.8-\mathrm{cm}$ aluminium disc that serves as a predator deterrent. Details about nestbox design and construction materials can be found in Lambrechts et al. (2010).

House wrens are small (10-12 g), insectivorous songbirds that readily accept nestboxes in lieu of natural cavities for nesting. House wrens in the central Illinois study population are migratory, arriving on the study area in late April-early May and leaving in September. They typically produce two broods each breeding season, the first in May with clutches of 6-8 eggs and the second in late June-early July with 5-7 eggs. Females lay one egg/d until the clutch is completed, incubate the eggs, which hatch after $\approx 12 \mathrm{~d}$, and brood young nestlings through the first two-thirds of the nestling period. Both males and females provision the nestlings after hatching, and male provisioning effort is positively correlated with survival and recruitment of nestlings to subsequent breeding populations (Bowers et al., 2014; Hodges et al., 2015). Nestlings fledge 15-18 d after hatching. See Johnson (2014) for additional information on house wren biology. 


\section{Field Procedures}

We began monitoring nestboxes for signs of occupation in early May 2017. Once egglaying began, we visited the boxes daily to check for the onset of incubation and to sort clutches visually into 'light' and 'dark' categories using Gosler indices (Gosler et al., 2000; Gosler et al., 2005). A single observer (KEH) assigned each egg of a clutch a score based on three characteristics: the darkness of the maculations, the distribution of maculations, and the darkness of the eggshell background. Each characteristic was scored on a scale of 0-5 in 0.5 increments, with higher scores indicating increased darkness or increased spread of maculation (Fig. A-2). The combined score of each characteristic formed the individual egg's score, which were averaged for the entire clutch. A midway point of 9.5 was chosen as the cutoff point, with clutch scores under 9.5 considered light and scores at or above 9.5 considered dark.

To assess the effects of clutch pigmentation on paternal provisioning we used a reciprocal cross-fostering design (Fig. A-3). Once assigned to a category, all the eggs in a clutch were swapped two days after incubation began with all the eggs in a second clutch of the same or opposite category. Eggs from the second nest were taken to the first nest to replace the artificial eggs left there earlier to keep females from abandoning an empty nest; females readily accepted and incubated these artificial eggs. For transport on foot between nests, eggs were placed in a padded cardboard egg carton. Clutches to be swapped were chosen based on similar laying date (no more than one day difference in clutch-initiation date), clutch size (no more than one egg difference), and distance (shorter travel times to minimize cooling during transport). This design created two experimental groups, light-dark clutch swaps (females producing light eggs incubating dark eggs) and dark-light swaps (females producing dark eggs incubating light eggs) and two control groups, dark-dark and light-light clutch swaps. 
We were concerned that a traditional cross-fostering experimental design would not identify the cause of any observed differences in provisioning. If we did a single swap, as described above, and detected an effect on provisioning, we would not be able to determine whether this was based on a pre-hatch assessment of eggshell pigmentation or a post-hatch assessment of nestling quality and behavior, or both (Riehl, 2011; Stoddard et al., 2012). Nestlings may advertise aspects of their fitness in various forms, such as begging (Gladbach et al., 2009; Noguera et al., 2010; Quillfeldt et al., 2010; Rodríguez-Gironés et al., 2001; Sacchi et al., 2002), and parents may use such advertisements to influence their investment (Bowers et al., 2019; Leonard \& Horn, 2001; MacGregor \& Cockburn, 2002; Tarwater et al., 2009), though this is not always the case (Barnett et al., 2011). To decouple 'expected' nestling quality (based on eggshell pigmentation) from 'actual' nestling quality (possibly conveyed through begging or another nestling feature), we included a second swap (returning nestlings to their biological parents) in our cross-fostering design. Cross-fostered clutches were left in their new nests for ten days to give males adequate exposure, after which they were returned to their original nests at a predicted two days prior to hatching for their biological parents to rear (Fig. A-3).

To evaluate male and female provisioning effort, a dummy camera in a cell-phone holster mounted on a $1.5-\mathrm{m}$ pole was placed $\approx 1 \mathrm{~m}$ from the entrance of each nestbox $\approx 24 \mathrm{~h}$ before recording began. On brood-day 4 or 5 (4-5 d after the first nestling hatched on brood-day 0 ), the dummy camera was replaced with a real camera (Kodak Zx1 or Zx5 digital camera, Eastman Kodak Company, Rochester, NY, USA) and $\approx 1.5$-hr recordings made between 06:00 AM and 09:00 AM Central Daylight Time, which ensured that we obtained 60 min of undisturbed provisioning behavior that began after the parents resumed normal activity (typically $<5 \mathrm{~min}$ ) Provisioning behavior was scored blind to the treatment by one person (CFT), who recorded the 
number of provisioning trips and prey size (small, medium, large relative to beak length; see Barnett et al., 2011) of both males and females. Not all nests survived to the end of the experiment. If a swap partner was depredated before eggs could be returned to their natal nest, they were left with their foster parents. A total of 53 swaps yield offspring that survived to fledging (13 light-light, 14 light-dark, 9 dark-dark, and 17 dark-light), of which provisioning was recorded at 37.

We measured body size (tarsus length measured to the nearest $0.1 \mathrm{~mm}$ with dial calipers) and mass (weighed to the nearest $0.5 \mathrm{~g}$ on an Acculab Pocket Pro PP201) of all adults and nestlings. Males and females were caught during incubation and fitted with a numbered, aluminium U.S. Geological Survey band; males were given an additional three coloured Darvic bands (total 2 bands/leg) to facilitate identification during provisioning. Nestlings were banded on brood-day 11 , weighed, and measured. A small $(\approx 40 \mu \mathrm{L})$ sample of blood, taken from the brachial vein of adults and nestlings, was stored on dry ice in the field. Upon return to the laboratory, the blood samples were transferred to a $-80^{\circ} \mathrm{C}$ freezer and stored for another study. Nests were then monitored daily for fledging success. We banded and collected a blood sample from 94 females and 315 nestlings.

Because visual scoring of egg pigmentation is not always reliable (Brulez et al., 2014a,b; Stoddard et al., 2012; Wegmann et al., 2015), we also took digital photographs of each egg before swapping. All photos were taken in the field on a standard black background from approximately $15 \mathrm{~cm}$ away (lighting conditions varied, but efforts were made to take all photos in moderate shade). These photos were later used for the purpose of verifying the visual classifications (see photo processing and machine learning section). We photographed 653 eggs from 97 nests. 


\section{Photo Processing and Machine Learning}

Although visual scoring systems were used in the field, previous studies have demonstrated they are not always reliable because of poor repeatability and a lack of correlation to actual pigment concentrations in the eggshell (Brulez et al., 2014a; Brulez et al., 2014b; Dainson et al., 2018; Wegmann et al., 2015). To address the first of these issues, we sought to verify the scoring system using computational methods. Using the software program ImageMagick (version 7.0.7-22, http://www.imagemagick.org), digital photographs of eggs were centered and then a $10 \%$ crop was applied resulting in a central strip running pole to pole to represent the entirety of the egg. These strips were further subdivided into 5 equal regions for evaluation of variation across each egg from pole to pole. A common threshold was applied to each image to differentiate maculation from background and to calculate percentage maculation. Numerical data were individually extracted from the strips and strip subregions, and the maculation and background regions of each strip, giving a total of seventeen variables (see Table A-3). Darkness variables were extracted from Red-Green-Blue (RGB) images, and the images were split into separate RGB channels to extract colour variables. The repeatability of a subset of these characters within clutches was calculated following Lessells and Boag (1987), and revealed that different dimensions of eggshell pigmentation were highly and significantly repeatable within clutches (Table A-1).

To classify each egg as dark or light we used an unsupervised machine learning approach to cluster our samples using all of the image data as input features. We determined the hierarchical relationships between the samples using a bottom-up agglomerative clustering approach (AGNES; implemented in the "cluster" package in R). Clusters were calculated using Ward's minimum variance method to create a dendrogram ("factoextra" package in R). To 
determine the number of clusters to use in our new classification, we used a silhouette plot, which revealed that three clusters (representing light, intermediate, and dark pigmentation categories) were better supported than our original two. Thus, our clutches were re-classified into one of three categories, going from the darkest eggs in cluster 1 to the lightest eggs in cluster 3.

To independently validate and aid in interpretation of the clusters identified by machine learning, we performed a principal components analysis (PCA) of four egg parameters that we had identified a priori as likely best capturing the different dimensions of egg pigmentation: percentage maculation (percentage of slice covered by pigment), mean darkness (average darkness of all pixels across the slice), Red value, and coefficient of variation in pigmentation darkness across the five regions. The PCA only returned one PC with an Eigenvalue greater than 1 and which explained $65 \%$ of all the variation in the four original variables (Table A-2). Based on the loadings of the original variables on PC1, PC1 scores can be interpreted as follows: high PC1 scores indicate lighter eggs, with less pigment coverage, lighter reds, and reduced variation across the slice whereas low PC1 scores indicate darker eggs, with greater pigment coverage, browner eggs, and increased variation across the slice. We then employed a mixed-model ANOVA with PC1 score as the dependent variable, AGNES cluster classification as the main effect, and nest as the random effect to evaluate how closely AGNES cluster predicts pigmentation darkness as assessed using PCA. AGNES cluster explained a significant proportion of the variation in PC1 scores $\left(F_{2,554}=261.1, \mathrm{P}<0.0001\right)$, and least-squares mean PC1 scores $( \pm \mathrm{SE})$ aligned closely with our machine-learning cluster classifications (cluster 1 (dark): $-0.93 \pm$ 0.09; cluster 2 (intermediate): $0.45 \pm 0.12$; cluster 3 (light): $1.44 \pm 0.10$ ).

All statistical analyses were done using median Agnes cluster score of a clutch as a categorical variable representing degree of whole-clutch pigmentation, except in one analysis 
where we used the median PC1 score as a dependent variable to evaluate the effect of female age and size on natal clutch pigmentation.

\section{Statistical Analyses}

We used SAS statistical software (version 9.4; SAS Institute, Cary, NC, U.S.A.) and all tests were two-tailed $(\alpha=0.05)$. We use Satterthwaite's degrees-of-freedom approximation, which can result in non-integer denominator degrees of freedom. Where appropriate, we included nest as a random effect to account for the statistical nonindependence of observations within the same nest.

We used a generalized linear model to assess the effect of foster clutch pigmentation on subsequent provisioning by males on brood-day 4 , with brood size and female provisioning rate (number of female feeds/hour) included as covariates.

We similarly used generalized linear models to evaluate the effects of natal clutch pigmentation on various components of the within-season reproductive success of females, including clutch size, hatching success, and the number of fledglings produced. To determine the effect of natal clutch pigmentation on the propensity of females to produce a second brood later in the breeding season, we employed a generalized linear mixed model (PROC GLIMMIX) with a binary response (produced a second brood or not), with pigmentation category as the main effect and nest as a random effect.

To assess the effects of female size and age on egg pigmentation and maculation, we used the median PC1 score derived for each clutch as the dependent variable, female age as the main effect (one or two years old), and tarsus length as a covariate.

To examine the effect of natal clutch pigmentation on the size-adjusted mass of nestlings, we employed a linear mixed model with natal clutch pigmentation and foster clutch pigmentation 
as main effects, tarsus length as a covariate, and nest as a random effect. We included foster clutch pigmentation based on our prediction that this would influence parental provisioning, and that this post-natal effect could, in turn, affect the condition of the offspring.

To determine the effect of natal clutch pigmentation on female return rates the following breeding season, we used a generalized linear mixed model (PROC GLIMMIX) with a binary response (returned or did not), with pigmentation as the main effect and nest as a random effect. Similarly, to assess the effect of natal clutch pigmentation on recruitment of offspring to the breeding population, we used a generalized linear mixed model with a binary response (recruited or did not), with nest as a random effect. 


\section{CHAPTER II: RESULTS AND DISCUSSION}

\section{Results}

\section{Effects on Paternal Provisioning}

There was no effect of pigmentation of the foster clutch on subsequent provisioning by

males on brood-day 4. Paternal provisioning of nestlings was inversely related to the feeding rate of the female (parameter estimate $\pm \mathrm{SE}=-0.60 \pm 0.29$ ) and increased with the number of nestlings in the brood (parameter estimate $=1.58 \pm 0.80$; Table A-4).

\section{Effects on Within-Season Reproductive Success}

There were no differences in clutch size in relation to the pigmentation category of the natal clutch $\left(F_{2,47}=0.59, P=0.56\right)$, although structurally larger females (as reflected by tarsus length) produced significantly larger clutches (parameter estimate $\pm \mathrm{SE}=0.38 \pm 0.18 ; F_{2,47}=$ $2.09, P=0.042)$. The mean clutch size of all females was $6.88 \pm 0.1$ eggs. There were no differences in hatching success in relation to the pigmentation category of the natal clutch $\left(F_{2,47}\right.$ $=0.60, P=0.55)$, and hatching success exceeded $86 \%$ in all three groups. There were also no differences between pigmentation categories in the total number of fledglings produced $\left(F_{2,48}=\right.$ $0.22, P=0.80)$. The likelihood of a female producing a second brood later in the breeding season was unrelated to the pigmentation of her initial natal clutch $\left(F_{2,47.9}=0.53, P=0.59\right)$.

\section{Egg Pigmentation and Maculation in Relation to Female Size and Age}

There was a significant effect of female age (i.e. year of banding) on natal clutch pigmentation (Fig A-5; $F_{2,48}=7.37, P=0.0092$ ); older females laid significantly lighter, less maculated eggs than younger females, which produced more darkly pigmented and densely maculated eggs; the effect of structural body size (i.e. tarsus length) was nearly significant $\left(F_{2,48}\right.$ $=3.35, P=0.0733$ ). The results (not shown) were qualitatively the same when we included 
female body mass in the model (i.e. age remained statistically significant and tarsus length, nearly so), but we opted for the simpler model because of missing values for body mass for three of our subjects.

\section{Effects on Offspring}

There was a significant effect of natal clutch pigmentation on size-adjusted nestling mass on brood-day 11, but there was no influence of the pigmentation of the foster clutch (Table A-5). Nestlings hatching from lighter, less maculated eggs were heavier than those hatching from more darkly pigmented and densely maculated eggs (Fig. A-6).

\section{Effects on Adult Return Rates and Offspring Recruitment}

Of the 51 females for which we recorded natal clutch pigmentation and which returned as breeders in 2017,15 returned to breed the following year. There were no significant differences in adult return rates in relation to the pigmentation category of the natal clutch $\left(F_{2,48}=0.59, P=\right.$ $0.56)$.

Of the 303 banded offspring produced in 2017, 13 were recruited to the breeding population (12 were captured in 2018, and one additional offspring in 2019). There were no significant differences in offspring recruitment in relation to the pigmentation category of the natal clutch $\left(F_{2,67.17}=2.27, P=0.11\right)$.

\section{Discussion}

The results of this study do not support our hypoS1 thesis that male provisioning is informed by eggshell pigmentation. Male provisioning was instead influenced by the number of nestlings and the degree of female provisioning. We did find, however, an association between clutch pigmentation and both female and offspring quality. 
In accordance with the poor-quality hypothesis, we found that older females laid significantly lighter eggs and tended to have a larger body size. The level of pigmentation in a female's clutch has been shown to change across time because of environmental influences such as food availability (Duval et al., 2015; Hargitai et al., 2017b; Morales et al., 2011; Moreno et al., 2006a) and climate (Avilés et al., 2007), although the majority of these studies have focused on the blue-green component of eggshell colouration. However, there is also considerable evidence of heritable genetic variation in certain aspects of eggshell pigmentation (Cassey et al., 2010; Gosler et al., 2000; Wang et al., 2013; Xu et al., 2018; Yuan \& Lu, 2007; Zheng et al., 2014) and, thus, eggshell pigmentation may remain fairly constant over a female's lifetime. As lifespan is often associated with an individual's condition and predictive of lifetime reproductive success (Blomqvist et al., 1997; Bowers et al., 2017; Cain \& Ketterson, 2012; Weber et al., 2018), older females might be considered to be of higher quality. Given that older females laid significantly lighter, less-maculated eggs, it follows that the pigmentation of the eggs that a female lays has the potential to convey reliable information about her quality, and that increased clutch pigmentation may be a sign of poorer quality.

Offspring that hatched from lighter, less maculated clutches of eggs were also of higher quality with respect to their size-adjusted mass, which is frequently taken as a measure of individual body condition (Barnett et al., 2015). Bowers et al. (2014) showed that mass was positively correlated with nestling survival and predictive of recruitment to the breeding population at our study site. Although we did not find any evidence that the nestlings from lighter clutches were more likely to return the following year, the number of recruits was probably too low to detect a difference (only 13 nestlings returned as adults). It is worth noting that the greater size-adjusted mass of nestlings hatching from lighter eggs cannot be attributed to 
increased parental provisioning. Thus, the effect on nestlings was likely not environmental, but related instead to maternal condition, although how the mother confers this benefit to her offspring, genetically or hormonally via the yolk, is unknown. Regardless of the underlying mechanism, this finding also supports the idea that eggshell pigmentation has the potential to be informative and that, at least in our study species, increased pigmentation is reflective of lowerquality individuals.

Our findings support a growing number of studies that suggest that protoporphyrin-based eggshell pigmentation can be used to infer female quality. As in our study, some of these have found that decreased eggshell pigmentation is associated with higher female quality (Badás et al., 2017; Duval et al., 2013b; Duval et al., 2015; Martínes-de la Puente et al., 2007; Stoddard et al., 2012; Walters \& Getty, 2010). However, there are still numerous studies with results that conflict with this pattern, finding that increased brown pigmentation is reflective of higher female quality (Holveck et al., 2012; Holveck et al., 2019; Martínez-Padilla et al., 2010; Mertens et al., 2010; Sanz \& García-Navas, 2009) or higher egg or nestling quality (Holveck et al., 2012; Poláček et al., 2017). Only a few studies have reported no connection between the degree of protoporphyrin-based pigmentation and female condition (Duval et al., 2013a; Giordano et al., 2015). Although the general consensus seems to be that eggshell pigmentation is informative, it is still difficult to determine whether the poor-quality or high-quality hypothesis is better supported. It is increasingly likely that the connection between brown eggshell pigmentation and female quality varies from species to species, and future research should attempt to investigate what connects those species that fall on one side of the divide versus those that fall on the other.

Our study is one of only a handful that has investigated whether or not protoporphyrinbased pigmentation affects the level of male parental investment. Of these, both Stoddard et al. 
(2012) and Bulla et al. (2012) also found no effect, although it is worth noting that Bulla et al. (2012) focused on incubation behavior and not provisioning, and it was strictly observational. Sanz and García-Navas (2009) found a higher rate of male provisioning to nestlings hatching from more heavily pigmented eggs, but their study design did not account for the effect of nestling quality. Walters et al. (2014) found that male house wrens provisioned more to nests in which an artificial white egg had been added than to nests in which an artificial brown egg had been added. However, this experiment also does not take into account the potential effect of confounding factors such as female or nestling quality. Poláček et al. (2017) found increased paternal provisioning in response to more heavily pigmented tree sparrow eggs, but their study was also observational. With this limited amount of evidence, it is difficult to assert with any certainty whether male birds attend to the eggshell pigmentation of their mates when subsequently provisioning their nestlings. Our study suggests they do not, despite evidence from us and other investigators that eggshell pigmentation can reveal important information about the quality of females. This raises the question: why do males not use this information to inform their investment in nestling provisioning?

One possible explanation for the lack of effect of eggshell on male provisioning is an inability to detect differences in pigmentation. This could be caused by poor lighting in cavity nests, which would limit a male's ability to observe clutch pigmentation (Cassey, 2009; Cassey et al., 2009; Reynolds et al., 2009). However, the results of modeling studies by Avilés et al. (2011) and Holveck et al. (2010) indicate that this may not be an issue, although both concluded more research is needed. Another hinderance to a male's observance of eggshell pigmentation may be opportunity. In species with female-only incubation, it is possible that males simply do not have sufficient access to eggs to make an evaluation based on pigmentation (Cassey et al., 
2009; Reynolds et al., 2009; Stoddard et al., 2012). However, this claim has been disputed in the case of blue tits (Holveck et al., 2010) and pied flycatchers (Ficedula hypoleuca, Moreno et al., 2005). Personal observation (KEH, CFT) of male house wrens on our study site indicates males frequently enter or partially enter the nestbox during egg laying and incubation when the female is absent. Thus, although they cannot be ruled out, lack of ability or opportunity to observe eggshell pigmentation are unlikely explanations for the absence of an effect of differences in eggshell pigmentation on male provisioning.

Perhaps the most parsimonious explanation for why males do not act on evidence of female quality offered by eggshell pigmentation, is that they are constrained by both the species' mating system and limited lifetime opportunities to reproduce. House wrens are primarily socially monogamous (Johnson, 2014), which means that in a population with a roughly equal sex ratio, many individuals will be paired with partners that are of lower-than-average quality. Thus, although a male may ascertain that his mate is of low quality, his opportunities to 'trade up' may be severely curtailed. Exacerbating the demand/supply mismatch with respect to the availability of high-quality mates, temperate-zone house wrens are short-lived with an average lifespan of an individual that reaches adulthood of less than two years (Johnson, 2014). Thus, males may be selected to invest a specific level of parental effort irrespective of the quality of their mate because the alternative is not to reproduce at all. Sexual selection on eggshell pigmentation is, therefore, more likely to be found in species that are longer-lived and have persistent pair-bonds (Cherry \& Gosler, 2010; Riehl, 2011).

In conclusion, we found that house wren females exhibit extensive variation in protoporphyrin-based eggshell pigmentation, and that various parameters of this pigmentation are significantly repeatable within clutches. Moreover, eggshell pigmentation appears to reveal 
reliable information about the quality of females and their young. Specifically, darker, more heavily maculated eggs seem to be indicative of lower quality individuals, in support of the poorquality hypothesis. Notwithstanding these obvious cues, male house wrens do not appear to adjust their parental provisioning in relation to the pigmentation of their mate's clutch. Although it seems likely that male house wrens are fully capable of observing eggshell pigmentation and may be able to infer female quality from it, the mating system of the species may greatly limit the ways in which males can respond adaptively to this information. The conflicting results of what eggshell pigmentation does, or does not, signal to males across different species of birds can probably best be resolved through consideration of variation in mating system and life history. However, such a comparative approach will require additional studies in which the effects of eggshell pigmentation are experimentally decoupled from the quality of young in eliciting parental solicitude. 


\section{REFERENCES}

Afonso, S., Vanore, G., \& Batlle, A. (1999) Protoporphyrin IX and oxidative stress. Free Radical Research, 31(3), 161-170.

Avilés, J. M., Stokke, B. G., Moksnes, A., Røskaft, E., \& Møller, A. P. (2007). Environmental conditions influence egg color of reed warblers Acrocephalus scirpaceus and their parasite, the common cuckoo Cuculus canorus. Behavioral Ecology and Sociobiology, 61(3), 475485. https://doi.org/10.1007/s00265-006-0275-0

Avilés, J. M., Soler, J. J., \& Hart, N. S. (2011). Sexual selection based on egg colour: physiological models and egg discrimination experiments in a cavity-nesting bird. Behavioral Ecology and Sociobiology, 65(9), 1721-1730. https://doi.org/10.1007/s00265011-1180-8

Badás, E. P., Martínez, J., Rivero-de Aguilar, J., Stevens, M., van der Velde, M., Komdeur, J., \& Merino, S. (2017). Eggshell pigmentation in the blue tit: male quality matters. Behavioral Ecology and Sociobiology, 71(3), 57. https://doi.org/10.1007/s00265-017-2286-4

Barnett, C. A., Clairardin, S. G., Thompson, C. F., \& Sakaluk, S. K. (2011). Turning a deaf ear: A test of the manipulating androgens hypothesis in house wrens. Animal Behaviour, 81(1), 113-120. https://doi.org/10.1016/j.anbehav.2010.09.019

Barnett, C. A., T. N. Suzuki, S. K. Sakaluk, \& Thompson, C. F. (2015). Mass-based condition measures and their relationship with fitness: in what condition is condition? Journal of Zoology, 296(1), 1-5. https://doi.org/10.1111/jzo.12213

Bischoff, C. M., \& Murphy, M. T. (1993). The detection of and responses to experimental intraspecific brood parasitism in eastern kingbirds. Animal Behaviour, 45(4), 631-638. https://doi.org/10.1006/anbe.1993.1079 
Blomqvist, D., Johansson, O., \& Götmark, F. (1997). Parental quality and egg size affect chick survival in a precocial bird, the lapwing Vanellus vanellus. Oecologia, 110(1), 18-24. https://doi.org/10.1007/s00442005012

Board, R. G., \& Sparks, N.H.C. (1991). Shell structure and formation in avian eggs. In D. C. Deeming \& M. W. J. Ferguson (Eds.), Egg Incubation: its Effects on Embryonic Development in Birds and Reptiles (71-86). Cambridge, Cambridge University Press.

Bowers, E. K., Nietz, D., Thompson, C. F., Sakaluk, S. K. (2014). Parental provisioning in house wrens: effects of varying brood size and consequences for offspring. Behavioral Ecology, 25(6), 1485-1493. https://doi.org/10.1093/beheco/aru153

Bowers, E. K., Sakaluk, S. K., \& Thompson, C. F. (2017). Interactive effects of parental age on offspring fitness and age-assortative mating in a wild bird. Journal of Experimental Zoology, 327(5), 302-310. https://doi.org/10.1002/jez.2090

Bowers, E. K., Jenkins, J. B., Mueller, A. J., Miller, K. D., Thompson, C. F., \& Sakaluk, S. K. (2019). Condition-dependent begging elicits increased parental investment in a wild bird population. American Naturalist, 193(5), 725-737. https://doi.org/10.1086/702848

Brulez, K., Cassey, P., Meeson, A., Mikšík, I., Webber, S. L., Gosler, A. G., \& Reynolds, S. J. (2014a). Eggshell spot scoring methods cannot be used as a reliable proxy to determine pigment quantity. Journal of Avian Biology, 45(1), 94-102. https://doi.org/10.1111/j.1600048X.2013.00236.X

Brulez, K., Choudhary, P.K., Maurer, G., Portugal, S. J., Boulton, R. L., Webber, S. L., \& Cassey, P. (2014b). Visual scoring of eggshell patterns has poor repeatability. Journal of Ornithology, 155(3), 701-705. https://doi.org/10.1007/s10336-014-1053-9. 
Bulla, M., Śálek, M., \& Gosler, A. G. (2012). Eggshell spotting does not predict male incubation but marks thinner areas of a shorebird's shells. Auk, 129(1), 26-35. https://doi.org/10.1525/auk.2012.11090

Burley, N. (1986). Sexual selection for aesthetic traits in species with biparental care. American Naturalist, 127(4), 415-445. https://doi.org/10.1086/284493

Byrne, P. G., \& Rice, W. R. (2006). Evidence for adaptive male mate choice in the fruit fly Drosophilia melanogastar. Proceedings of the Royal Society Biological Sciences, 273(1589), 917-922. https://doi.org/10.1098/rspb.2005.3372

Cain, K. E., \& Ketterson, E. D. (2012). Competitve females are successful females; phenotype, mechanism, and selection in a common songbird. Behavioral Ecology and Sociobiology, 66(2), 241-252. https://doi.org/10.1007/s00265-011-1272-5

Casini, S., Fossi, M. C., Gavilan, J. F., Barra, R., Parra, O., Leonzio, C., \& Focardi, S. (2001). Porphyrin levels in excreta of sea birds of the Chilean coasts as nodestructive biomarker of exposure to environmental pollutants. Archives of Environmental Contamination and Toxicology, 41(1) 65-72. https://doi.org/10.1007/s002440010221

Cassey, P. (2009). Biological optics: seeing colours in the dark. Current Biology, 19(23), 10831084. https://doi.org/10.1016/j.cub.2009.10.014

Cassey, P., Ewens, J. G., Marshall, N. J., Vorobyev, M., Blackburn, T. M., \& Hauber, M. E. (2009). Are avian eggshell colours effective intraspecific communication signals in the Muscicapoidea? A perceptual modeling approach. Ibis, 151(4), 689-698. https://doi.org/10.1111/j.1474-919X.2009.00953.x 
Cassey, P., Portugal, S. J., Maurer, G., Ewen, J. G., Boulton, R.L., Hauber, M. E., \& Blackburn, T. M. (2010) Variability in avian eggshell colour: a comparative study of museum eggshells. PLoS ONE, 5(8), e12054. https://doi.org/10.1371/journal.pone.0012054

Cassey, P., Mikšík, I., Portugal, S. J., Maurer, G., Ewen, J. G., Zarate, E., Sewell, M. A., Karadas, F., Grim, T., \& Hauber, M. E. (2012). Avian eggshell pigments are not consistently correlated with colour measurements or egg constituents in two Turdus thrushes. Journal of Avian Biology, 43(6), 503-512. https://doi.org/10.1111/j.1600048X.2012.05576.X

Cherry, M. I., \& Gosler, A. G. (2010). Avian eggshell coloration: new perspectives on adaptive explanations. Biological Journal of the Linnean Society, 100, 753-762.

Dainson, M., Mark, M., Hossain, M., Yoo, B., Holford, M., McNeil, S. E., Riehl, C., \& Hauber, M. E. (2018). How to make a mimic? Brood parasitic striped cuckoo eggs match host shell color but not pigment concentrations. Journal of Chemical Ecology, 44(10), 940-946. https://doi.org/10.1007/s10886-018-0986-5

De Coster, G., De Neve, L., \& Lens, L. (2013). Intra-clutch variation in avian eggshell pigmentation covaries with female quality. Journal of Ornithology, 154(4), 1057-1065. https://doi.org/10.1007/s10336-013-0974-z

Dowling, D. K., \& Simmons, L. W. (2009). Reactive oxygen species as universal constraints in life-history evolution. Proceedings of the Royal Society, Biological Sciences, 276(1663), 1737-1745. https://doi.org/10.1098/rspb.2008.1791

Duval, C., Cassey, P., Lovell, P. G., Mikšík, I., Reynolds, S. J., \& Spencer, K. A. (2015). Maternal influence on eggshell maculation: implications for cryptic camouflaged eggs. Journal of Ornithology, 157(1), 303-310. https://doi.org/10.1007/s10336-015-1278-2 
Duval, C., Cassey, P., Lovell, P. G., Mikšík, I., Reynolds, S. J., \& Spencer, K. A. (2013a).

Eggshell appearance does not signal maternal corticosterone exposure in Japanese quail: an experimental study with brown-spotted eggs. PLoS ONE, 8(12). https://doi.org/10.1371/journal.pone.0080485

Duval, C., Cassey, P., Miksík, I., Reynolds, S. J., \& Spencer, K. A. (2013b). Conditiondependent strategies of eggshell pigmentation: an experimental study of Japanese quail (Coturnix coturnix japonica). Journal of Experimental Biology, 216(4), 700-708. https://doi.org/10.1242/jeb.077370

Edwards, D. A., \& Chapman, T. (2011). The evolution and significance of male mate choice. Trends in Ecology \& Evolution, 26(12), 647-654. https://doi.org/10.1016/j.tree.2011.07.012

Finkel, T., \& Holbrook, N. J. (2000) Oxidants, oxidative stress and the biology of ageing. Nature, 408(6809):239-247. https://dio.org/10.1038/35041687

Giordano, M., Constantini, D., Pick, J. L., \& Tschirren, B. (2015). Female oxidative status, egg antioxidant protection and eggshell pigmentation: a supplemental feeding experiment in great tits. Behavioral Ecology and Sociobiology, 69(5), 777-785. https://doi.org/10.1007/s00265-015-1893-1

Gladbach, A., Braun, C., Nordt, A., Peter, H., \& Quillfeldt, P. (2009). Chick provisioning and nest attendance of male and female Wilson's storm petrels Oceanites oceanicus. Polar Biology, 32(9), 1315-1321. https://doi.org/10.1007/s00300-009-0628-z

Gosler, A. G., Barnett, P. R., \& Reynolds, S. J. (2000). Inheritance and variation in eggshell patterning in the great tit Parus major. Proceedings of the Royal Society,Biological Sciences, 267(1461), 2469-2473. https://doi.org/10.1098/rspb.2000.1307 
Gosler, A. G., Higham, J. P., \& Reynolds, S. J. (2005). Why are birds' eggs speckled? Ecology Letters, 8(10), 1105-1113. https://doi.org/10.1111/j.1461-0248.2005.00816.x

Griffith, S. C., Barr, I., Sheldon, B. C., Rowe, L. V., \& Burke, T. (2009). Egg patterning is not a reliable indicatior of intraspecific brood parasitism in the blue tit Cyanistes caeruleus. Journal of Avian Biology, 40(3), 337-341. https://doi.org/10.1111/j.1600048X.2009.04671.x

Grinstein, M., Banneran, R. M., \& Moore, C. V. (1959). The utilization of protoporphyrin 9 in heme synthesis. Blood, 14(4), 476-485.

Hargitai, R., Nagy, G., Herényi, M., Nyiri, Z., Laczi, M., Hegyi, G., Eke, Z., \&Török, J. (2016). Darker eggshell spotting indicates lower yolk antioxidant level and poorer female quality in the Eurasian great tit ( Parus major ). Auk, 133(2), 131-146. https://doi.org/10.1642/AUK-15-128.1

Hargitai, R. (2017a). Eggshell biliverdin and protoporphyrin pigments in a songbird : are they derived from erythrocytes, blood plasma, or the shell gland? Physiological and Biochemical Zoology, 90(6), 613-626. https://doi.org/10.1086/694297

Hargitai, R., Boross, N., Nyiri, Z., \& Eke, Z. (2017b). Effects of food limitation on the intensity of blue-green and brown eggshell coloration: an experimental study with the canary. Journal of Avian Biology, 49(1), e01486. https://doi.org/10.1111/jav.01486

Hauber, M. E. (2014). The book of eggs: a life-size guide to the eggs of six hundred of the world's bird species. University of Chicago Press.

Hodges, C. J., Bowers, E. K., Thompson, C. F., \& Sakaluk, S. K. (2015). Cascading costs of reproduction in female house wrens induced to lay larger clutches. Journal of Evolutionary Biology, 28(7), 1383-1393. https://doi.org/10.1111/jeb.12662 
Holveck, M. J., Doutrelant, C., Guerreiro, R., Perret, P., Gomez, D., \& Grégoire, A. (2010). Can eggs in a cavity be a female secondary sexual signal? Male nest visits and modeling of egg visual discrimination in blue tits. Biology Letters, 6(4), 453-457. https://doi.org/10.1098/rsbl.2009.1044

Holveck, M. J., Grégoire, A., Staszewski, V., Guerreiro, R., Perret, P., Boulinier, T., \& Doutrelant, C. (2012). Eggshell spottiness reflects maternally transferred antibodies in blue tits. PLoS ONE, 7(11). https://doi.org/10.1371/journal.pone.0050389

Holveck, M., Guerreiro, R., Perret, P., Doutrelant, C., \& Grégoire, A. (2019). Eggshell coloration indicates female condition during egg-laying : a field experiment in blue tits. Biological Journal of the Linnean Society, blz082, 1-20. https://doi.org/10.1093/biolinnean/blz082

Johnson, L.S. (2014). House wren (Troglodytes aedon). In: Poole, A., editor. The birds of North America online, 2nd ed. Ithaca (NY): Cornell Lab of Ornithology and American Ornithologists' Union.

Jones, K. M., Monaghan, P., \& Nager, R. G. (2001). Male mate choice and female fecundity in zebra finches. Animal Behaviour, 62(6), 1021-1026. https://doi.org/10.1006/anbe.2001.1843

Kennedy, G. Y., \& Vevers, H. G. (1973). Eggshell pigments of the Araucano fowl. Comparative Biochemistry and Physiology B, 44(1), 11-25. https://doi.org/10.1016/03050491(73)90336-2

Kilner, R. M. (2006). The evolution of egg colour and patterning in birds. Biological Reviews, $81,383-406$.

Lahti, D. C., \& Lahti, A. R. (2002). How precise is egg discrimination in weaverbirds? Animal Behaviour, 63(6), 1135-1142. https://doi.org/10.1006/anbe.2002.3009 
Lambrechts, M. M., Adriaensen, F., Ardia, D. R., Artemyev, A. V., Atiénzar, F., Bańbura, J., Barba, E., et al. (2010). The design of artificial nestboxes for the study of secondary holenesting birds: a review of methodological inconsistencies and potential biases. Acta Ornithologica, 45(1), 1-26. https://doi.org/10.3161/000164510X516047

Lang, M. R., \& Wells, J. W. (1987). A review of eggshell pigmentation. World's Poultry Science Journal, 43(3), 238-246. https://doi.org/10.1079/WPS19870016

Lavelin, I., Meiri, N., \& Pines, M. (2000). New insight in eggshell formation. Poultry Science, 79(7), 1014-1017. https://doi.org/10.1093/ps/79.7.1014

Leonard, M. \& Horn, A. (2001). Begging calls and parental feeding decisions in tree swallows (Tachycineta bicolor). Behavorial Ecology and Sociobiology, 49(2-3), 170-175. https://doi.org/10.1007/s002650000290

Lessells, C., \& Boag, P. (1987). Unrepeatable repeatabilities: a common mistake. The Auk, 104(1), 116-121. doi:10.2307/4087240

London, I. M., Shemin, D., West, R., \& Rittenberg, D. (1949). Heme synthesis and red blood cell dynamics in normal humans and in subjects with polycythemia vera, sickle-cell anemia, and pernicious anemia. Journal of Biological Chemistry, 179(1), 463-484.

Lyon, B. E. (1993). Tactics of parasitic American coots: host choice and the pattern of egg dispersion among host nests. Behavioral Ecology and Sociobiology, 33(2), 87-100. https://doi.org/10.1007/BF00171660

MacGregor, N. A., \& Cockburn, A. (2002). Sex differences in parental response to begging nestlings in superb fairy-wrens. Animal Behaviour, 63(5), 923-932.

https://doi.org/10.1006/anbe.2001.1991 
Martínez-Padilla, J., Dixon, H., Vergara, P., Pérez-Rodríguez, L., \& Fargallo, J. A. (2010). Does egg colouration reflect male condition in birds? Naturwissenschaften, 97(5), 469-477. https://doi.org/10.1007/s00114-010-0660-4

Martínez-De La Puente, J., Merino, S., Moreno, J., Tomás, G., Morales, J., Lobato, E., GarcíaFraile, S., \& Martínez, J. (2007). Are eggshell spottiness and colour indicators of health and condition in blue tits Cyanistes caeruleus? Journal of Avian Biology, 38(3), 377-384. https://doi.org/10.1111/j.0908-8857.2007.03877.x

Mertens, K., Vaesen, I., Loffel, J., Kemps, B., Kamers, B., Perianu, C., Zoons, J., Darius, P., Decuypere, E., De Baerdemaeker, J., \& De Ketelaere, B. (2010). The transmission color value: a novel egg quality measure for recording shell color used for monitoring the stress and health status of a brown layer flock. Poultry Science, 89(3), 609-617. https://doi.org/10.3382/ps.2009-00261.

Mikšík, I., Holáň, V., \& Deyl, Z. (1996). Avian eggshell pigments and their variability. Comparative Biochemistry and Physiology Part B: Biochemistry and Molecular Biology, 113(3), 607-612. https://doi.org/10.1016/0305-0491(95)02073-X

Mittler, R. (2002). Oxidative stress, antioxidants and stress tolerance. Trends in Plant Science, 7(9), 405-410. https://doi.org/10.1016/S1360-1385(02)02312-9

Morales, J., Velando, A., \& Torres, R. (2011). Biliverdin-based egg coloration is enhanced by carotenoid supplementation. Behavioral Ecology and Sociobiology, 65(2), 197-203. https://doi.org/10.1007/s00265-010-1025-x

Moreno, J., Morales, J., Lobato, E., Merino, S., Tomás, G. (2005). Evidence for the signaling function of egg color in the pied flycatcher Ficedula hypoleuca. Behavioral Ecology, 16(5), 931-937. https://doi.org/10.1093/beheco/ari072 
Moreno, J., Lobato, E., Morales, J., Merino, S., Tomás, G., Martínez-de la Puente, J., Sanz, J., Mateo, R., \& Soler, J. J. (2006a). Experimental evidence that egg color indicates female condition at laying in a songbird. Behavioral Ecology, 17(4), 651-655. https://doi.org/10.1093/beheco/ark014

Moreno, J., Morales, J., Lobato, E., Merino, S., Tomás, G., \& Martínez-De La Puente, J. (2006b). More colourful eggs induce a higher relative paternal investment in the pied flycatcher Ficedula hypoleuca: A cross-fostering experiment. Journal of Avian Biology, 37(6), 555-560. https://doi.org/10.1111/j.2006.0908-8857.03915.x

Moreno, J., \& Osorno, J. L. (2003). Avian egg colour and sexual selection: does eggshell pigmentation reflect female condition and genetic quality? Ecology Letters, 6(9), 803806. https://doi.org/10.1046/j.1461-0248.2003.00505.x

Morgan, R. O., Naglie, G., Horrobin, D. F., \& Barbeau, A. (1979). Erythrocyte protoporphyrin levels in patients with Friedreich's and other ataxias. Canadian Journal of Neurological Sciences / Journal Canadien Des Sciences Neurologiques, 6(2), 227-232. doi:10.1017/S0317167100119699

Noguera, J. C., Morales, J., Pérez, C., \& Velando, A. (2010). On the oxidative cost of begging: antioxidants enhance vocalizations in gull chicks. Behavioral Ecology, 21(3), 479-484. https://doi.org/10.1093/beheco/arq005

Nys, Y., Hincke, M. T., Arias, J. L., Garcia-Ruiz, J. M., \& Solomon, S. E. (1999). Avian eggshell mineralization. Poultry and Avian Biology Reviews, 10(3), 143-166.

Poláček, M., Griggio, M., Mikšík, I., Bartíková, M., Eckenfellner, M., \& Hoi, H. (2017). Eggshell coloration and its importance in postmating sexual selection. Ecology and Evolution, 7(3), 941-949. https://doi.org/10.1002/ece3.2664 
Quillfeldt, P., Poisbleau, M., Mundry, R., \& Masello, J. (2010). Are acoustical parameters of begging call elements of thin-billed prions related to chick condition? Acta Ethologica, 13(1), 1-9. https://doi.org/10.1007/s10211-009-0066-5

Reynolds, S. J., Martin, G. R., \& Cassey, P. (2009). Is sexual selection blurring the functional significance of eggshell coloration hypotheses? Animal Behaviour, 78(1), 209-215. https://doi.org/10.1016/j.anbehav.2009.03.003

Riehl, C. (2011). Paternal investment and the "sexually selected hypothesis" for the evolution of eggshell coloration: revisiting the assumptions. Auk, 128(1), 175-179. https://doi.org/10.1525/auk.2011.10171

Rodríguez-Gironés, M. A., Zúñiga, J. M., \& Redondo, T. (2001). Effects of begging on growth rates of nestling chicks. Behavioral Ecology, 12(3), 269-274, https://doi.org/10.1093/beheco/12.3.269

Sacchi, R., Saino, N., \& Galeotti, P. (2002). Features of begging calls reveal general condition and need of food of barn swallow (Hirundo rustica) nestlings. Behavioral Ecology, 13(2), 268-273. https://doi.org/10.1093/beheco/13.2.268

Samiullah, S., Roberts, J. R., \& Chousalkar, K. (2015). Eggshell color in brown-egg laying hens - a review. Poultry Science, 94(10), 2566-2575. http://doi.org/10.3382/ps/pev202.

Sanz, J. J., \& García-Navas, V. (2009). Eggshell pigmentation pattern in relation to breeding performance of blue tits Cyanistes caeruleus. Journal of Animal Ecology, 78(1), 31-41. https://doi.org/10.1111/j.1365-2656.2008.01465.x

Sies, H. (1997). Oxidative stress: oxidants and antioxidants. Experimental Physiology, 82(2), 291-295. https://doi.org/10.1113/expphysiol.1997.sp004024 
Stoddard, M. C., Fayet, A. L., Kilner, R. M., \& Hinde, C. A. (2012). Egg speckling patterns do not advertise offspring quality or influence male provisioning in great tits. PLOS ONE, 7(7). https://doi.org/10.1371/journal.pone.0040211

Stoddard, M. C., Kilner, R. M., \& Town, C. (2014). Pattern recognition algorithm reveals how birds evolve individual egg pattern signatures. Nature Communications, 5(May), 1-10. https://doi.org/10.1038/ncomms5117

Tarwater, C. E., Kelley, J. P., \& Brawn, J. D. (2009). Parental response to elevated begging in a high predation, tropical environment. Animal Behaviour, 78(5), 1239-1245. https://doi.org/10.1016/j.anbehav.2009.07.040

Tinbergen, N., Broekhuysen, G. J., Feekes, F., Houghton, J. C. W., Kruuk, H., \& Szulc, E. (1962). Egg shell removal by the black-headed gull, Larus ridibundus L.: a behaviour component of camouflage. Behaviour, 19(1/2), 74-117

Trivers, R. (1972). Parental investment and sexual selection. In: Campbell, B., editor. Sexual selection and the descent of man. Chicago (IL): Aldine Press.

Walters, L. A., \& Getty, T. (2010). Are brighter eggs better? Egg color and parental investment by house wrens. Journal of Field Ornithology, 81(2), 155-166. https://doi.org/10.1111/j.1557-9263.2010.00273.x

Walters, L. A., Olszewski, N., \& Sobol, K. (2014). Male house wrens provide more parental provisioning to nests with a brighter artificial egg. Wilson Journal of Ornithology, 126(3), 508-515. https://doi.org/10.1676/13-221.1

Wang, X., Deng, X., Zhao, C., Li, J., Xu, G., Lian, L., \& Wu, C. (2007). Study of the deposition process of eggshell pigments using an improved dissolution method. Poultry Science, 86(10), 2236-2238. https://doi.org/10.1093/ps/86.10.2236 
Wang, Z., Qu, L., Yao, J., Yang, X., Li, G., Zhang, Y., Li, J., Wang, X., Bai, J., Xu, G., Deng, X., Yang, N., \& Wu, C. (2013) An EAV-HP insertion in 5' flanking region of SLCO1B3 causes blue eggshell in the chicken. PLoS Genetics, 9(1), e1003183. https://doi.org/10.1371/journal.pgen.1003183

Weber, B. M., Bowers, E. K., Terrell, K. A., Falcone, J. F., Thompson, C. F., \& Sakaluk, S. K. (2018). Pre- and post-natal effects of experimentally manipulated maternal corticosterone on growth, stress reactivity, and survival of nestling house wrens. Functional Ecology, 32(8), 1995-2007. https://doi.org/10.1111/1365-2435.13126

Wegmann, M., Vallat-Michel, A., \& Richner, H. (2015). An evaluation of different methods for assessing eggshell pigmentation and pigment concentration using great tit eggs. Journal of Avian Biology, 46(6), 597-607. https://doi.org/10.1111/jav.00495

Weidinger, K. (2001). Does egg colour affect predation rate on open passerine nests? Behavioral Ecology and Sociobiology, 49(6), 456-464. https://doi.org/10.1007/s002650100324

Xu, F. Q., Li, A., Lan, J. J., Wang, Y. M., Yan, M. J., Lian, S. Y., \& Wu, X. (2018). Study of formation of green eggshell color in ducks through global gene expression. PLoS ONE, 13(1), e0191564. https://doi.org/10.1371/journal.pone.0191564

Yuan, Q. Y., \& Lu, L. Z. (2007). Progresses in inheritance of genes for avian eggshell color. Hereditas (Beijing), 29(3), 265-268. https://doi.org/10.1360/yc-007-0265

Zhao, R., Xu, G., Liu, Z., Li, J., \& Yang, N. (2006). A study on eggshell pigmentation : biliverdin in blue-shelled chickens. Poultry Science, 85(3), 546-549. https://doi.org/10.1093/ps/85.3.546 
Zheng, C., Li, Z., Yang, N., \& Ning, Z. (2014). Quantitative expression of candidate genes affecting eggshell color. Animal Science Journal, 85(5), 506-510. https://doi.org/10.1111/asj.12182 


\section{APPENDIX A: TABLES AND FIGURES}

TABLE A-1. Repeatability of selected egg pigmentation parameters within clutches.

\begin{tabular}{|l|l|c|l|}
\hline Trait & $r_{i}$ & $F_{96,556}$ & $P$ \\
\hline $\begin{array}{l}\text { Percent maculation } \\
\text { cover }\end{array}$ & 0.37 & 4.97 & $<0.0001$ \\
\hline Mean Darkness & 0.43 & 5.99 & $<0.0001$ \\
\hline Darkness Pigmented & 0.57 & 10.05 & $<0.0001$ \\
\hline Redness & 0.63 & 12.31 & $<0.0001$ \\
\hline Red & 0.53 & 8.50 & $<0.0001$ \\
\hline CV & 0.63 & 12.65 & $<0.0001$ \\
\hline
\end{tabular}


TABLE A-2. Principal components analysis of selected egg pigmentation parameters.

\begin{tabular}{|l|l|l|l|}
\hline Component & \multicolumn{3}{|c|}{ Eigenvalues of correlation matrix } \\
\hline & Eigenvalue & $\begin{array}{l}\text { Proportion of variation } \\
\text { explained }\end{array}$ & Cumulative \\
\hline PC1 & 2.601 & 0.65 & 0.65 \\
\hline PC2 & 0.928 & 0.23 & 0.88 \\
\hline PC3 & 0.402 & 0.10 & 0.98 \\
\hline PC4 & 0.068 & 0.02 & 1.000 \\
\hline
\end{tabular}

\begin{tabular}{|l|l|l|l|l|}
\hline Component & \multicolumn{4}{|c|}{ Eigenvectors } \\
\hline $\begin{array}{l}\text { Percent } \\
\text { maculation cover }\end{array}$ & PC1 & PC2 & PC3 & PC4 \\
\hline $\begin{array}{l}\text { Mean darkness* } \\
\begin{array}{l}\text { Red RGB } \\
\text { value** }\end{array}\end{array}$ & 0.576 & 0.565 & -0.157 & 0.632 \\
\hline $\begin{array}{l}\text { Coefficient of } \\
\text { variation }\end{array}$ & -0.424 & -0.324 & -0.003 & 0.750 \\
\hline
\end{tabular}

*smaller values $=$ darker eggs

$* *$ smaller values $=$ browner eggs 
TABLE A-3. The seventeen variables of data extracted from digital egg photos.

\begin{tabular}{|c|c|}
\hline Variables & Description \\
\hline Mean Darkness & Mean pixel darkness value from the whole egg slice \\
\hline $\begin{array}{l}\text { Minimum } \\
\text { Darkness }\end{array}$ & Minimum pixel darkness value from the whole egg slice \\
\hline $\begin{array}{l}\text { Maximum } \\
\text { Darkness }\end{array}$ & Maximum pixel darkness value from the whole egg slice \\
\hline Standard Deviation & Standard deviation of pixel darkness from the whole egg slice \\
\hline Red & Mean red channel pixel value of whole egg slice \\
\hline Green & Mean green channel pixel value of whole egg slice \\
\hline Blue & Mean blue channel pixel value of whole egg slice \\
\hline $\begin{array}{l}\text { Coefficient of } \\
\text { Variance }\end{array}$ & Coefficient of variance between regions of egg slice \\
\hline$\%$ Pigmented & Percent of whole egg slice covered by darker maculations \\
\hline $\begin{array}{l}\text { Unpigmented Mean } \\
\text { Darkness }\end{array}$ & $\begin{array}{l}\text { Mean pixel darkness value from the lighter background area of the } \\
\text { whole egg slice }\end{array}$ \\
\hline Unpigmented Red & $\begin{array}{l}\text { Mean red channel value from the lighter background area of the whole } \\
\text { egg slice }\end{array}$ \\
\hline $\begin{array}{l}\text { Unpigmented } \\
\text { Green }\end{array}$ & $\begin{array}{l}\text { Mean green channel value from the lighter background area of the whole } \\
\text { egg slice }\end{array}$ \\
\hline Unpigmented Blue & $\begin{array}{l}\text { Mean blue channel value from the lighter background area of the whole } \\
\text { egg slice }\end{array}$ \\
\hline $\begin{array}{l}\text { Pigmented Mean } \\
\text { Darkness }\end{array}$ & Mean pixel darkness value from the maculations of the whole egg slice \\
\hline Pigmented Red & Mean red channel value from the maculations of the whole egg slice \\
\hline Pigmented Green & Mean green channel value from the maculations of the whole egg slice \\
\hline Pigmented Blue & Mean blue channel value from the maculations of the whole egg slice \\
\hline
\end{tabular}


TABLE A-4. Effects of foster egg maculation and pigmentation on paternal provisioning.

\begin{tabular}{|l|l|l|l|}
\hline Effect & $\boldsymbol{F}$ & $\boldsymbol{d f}$ & $\boldsymbol{P}$ \\
\hline Foster egg pigmentation & 1.26 & 2,31 & 0.30 \\
\hline Number of female feeds & 4.33 & 1,31 & 0.0458 \\
\hline Number of young at brood-day 4 & 3.96 & 1,31 & 0.0555 \\
\hline
\end{tabular}


TABLE A-5. Effects of natal and foster egg maculation and pigmentation on size-adjusted nestling mass on brood-day 11.

\begin{tabular}{|l|l|l|l|}
\hline Effect & $\boldsymbol{F}$ & $\boldsymbol{d} \boldsymbol{P}$ & \\
\hline Natal egg pigmentation & 3.80 & $2,43.51$ & 0.0302 \\
\hline Foster egg pigmentation & 1.50 & $2,43.55$ & 0.235 \\
\hline Tarsus length & 83.45 & $1,289.4$ & $<0.0001$ \\
\hline
\end{tabular}




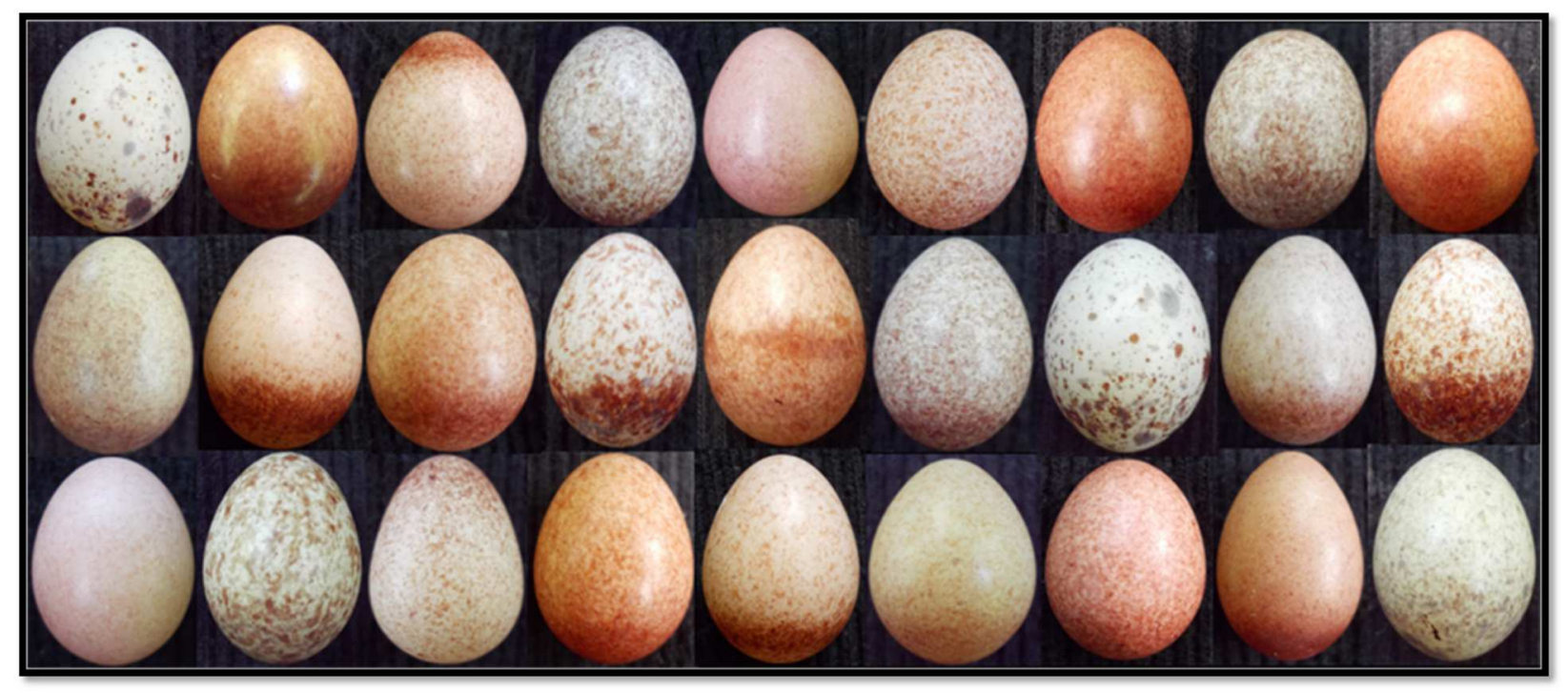

FIGURE A-1. House wren (Troglodytes aedon) eggs from different nests produced on the study areas in the same year. 


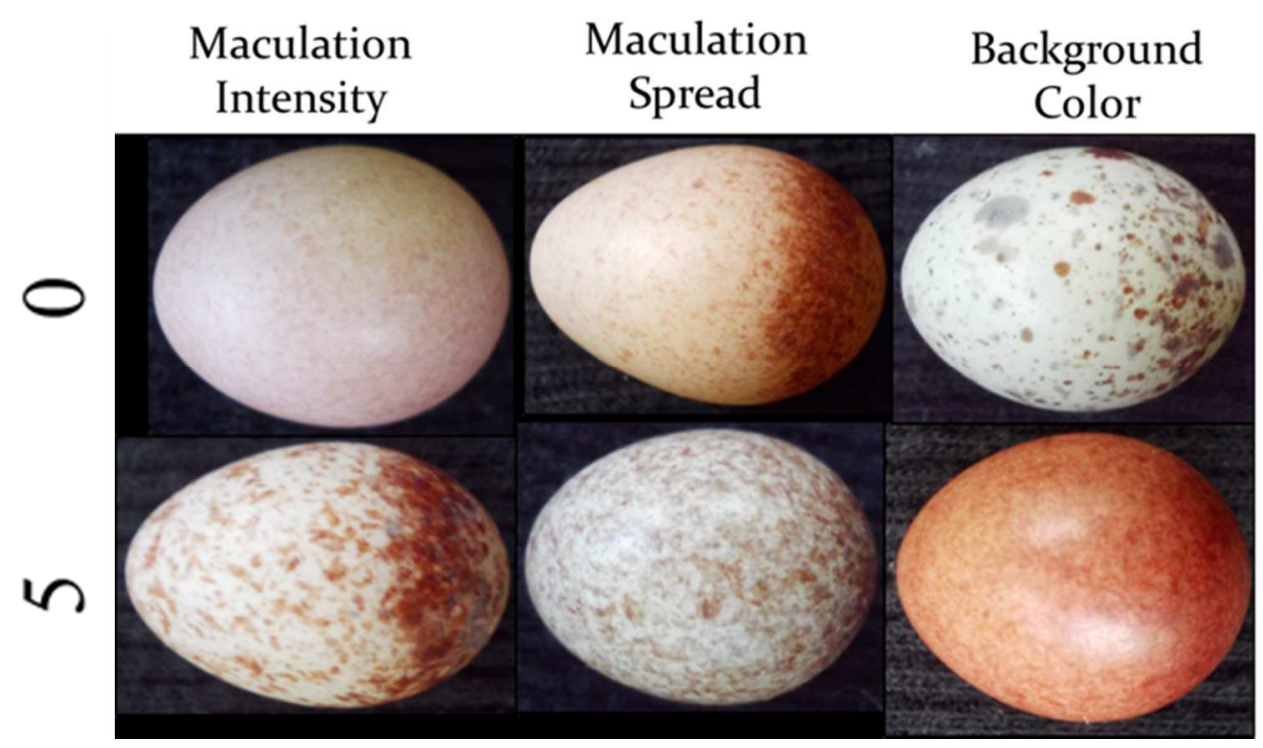

FIGURE A-2. Each egg in each clutch was digitally photographed and scored based on three parameters: maculation intensity (darkness), maculation spread, and background pigmentation darkness. Scores for each parameter ranged from 0 , representing the lower extreme (very pale maculations, very concentrated maculation spread, and very pale eggshell background), to 5 , representing the upper extreme (very dark maculations, dispersed maculations, and very dark eggshell background). The scores for each category were added to create a total score for each egg, which was then averaged over the clutch. Higher scores denoted more pigmented or darker clutches while lower scores indicated less pigmented or lighter clutches. 

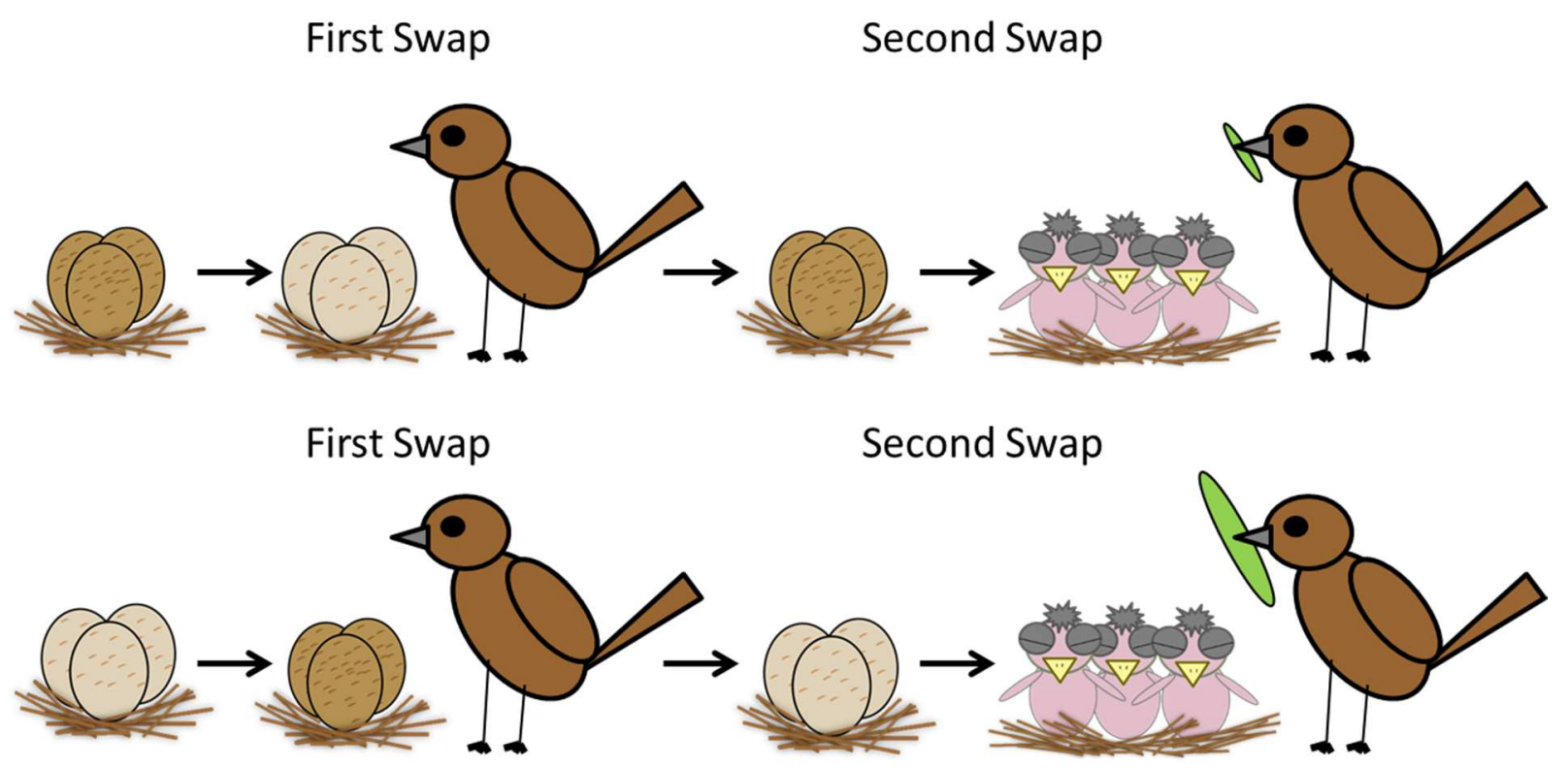

FIGURE A-3. Schematic of clutch cross-fostering design used to test whether male provisioning responds to clutch pigmentation. In experimental replicates, dark clutches were swapped with light clutches two days into incubation, whereas in control replicates, light clutches were swapped with light clutches, or dark clutches with dark. Foster eggs remained in the nest for ten days to allow the male ample opportunity to observe and evaluate them. At an estimated two days prior to hatching, clutches were returned to their original nest to avoid the confounding effect of nestling quality on male provisioning effort. 


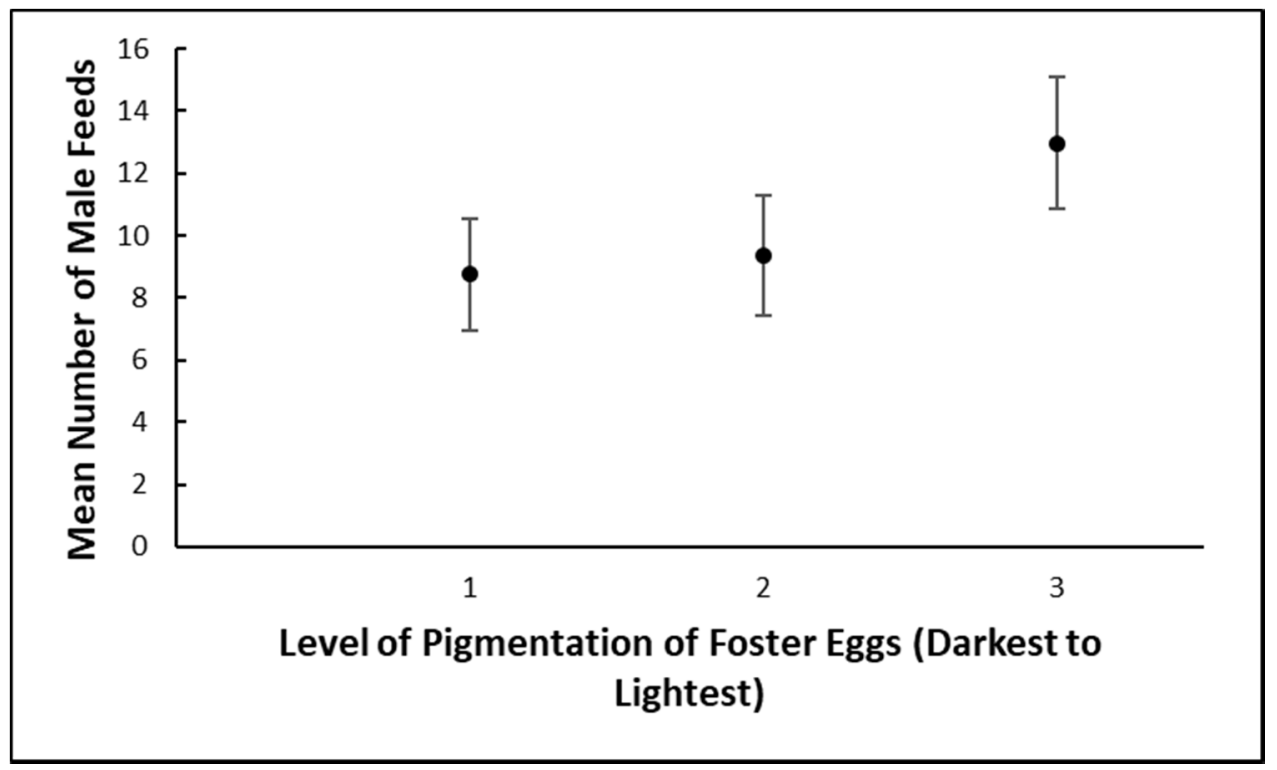

FIGURE A-4. Least-squares mean number of male feeding trips $( \pm \mathrm{SE})$ on brood-day four in relation to the eggshell pigmentation cluster (in which cluster 1 is the darkest category and cluster 3 is the lightest category) of the eggs males fostered. 


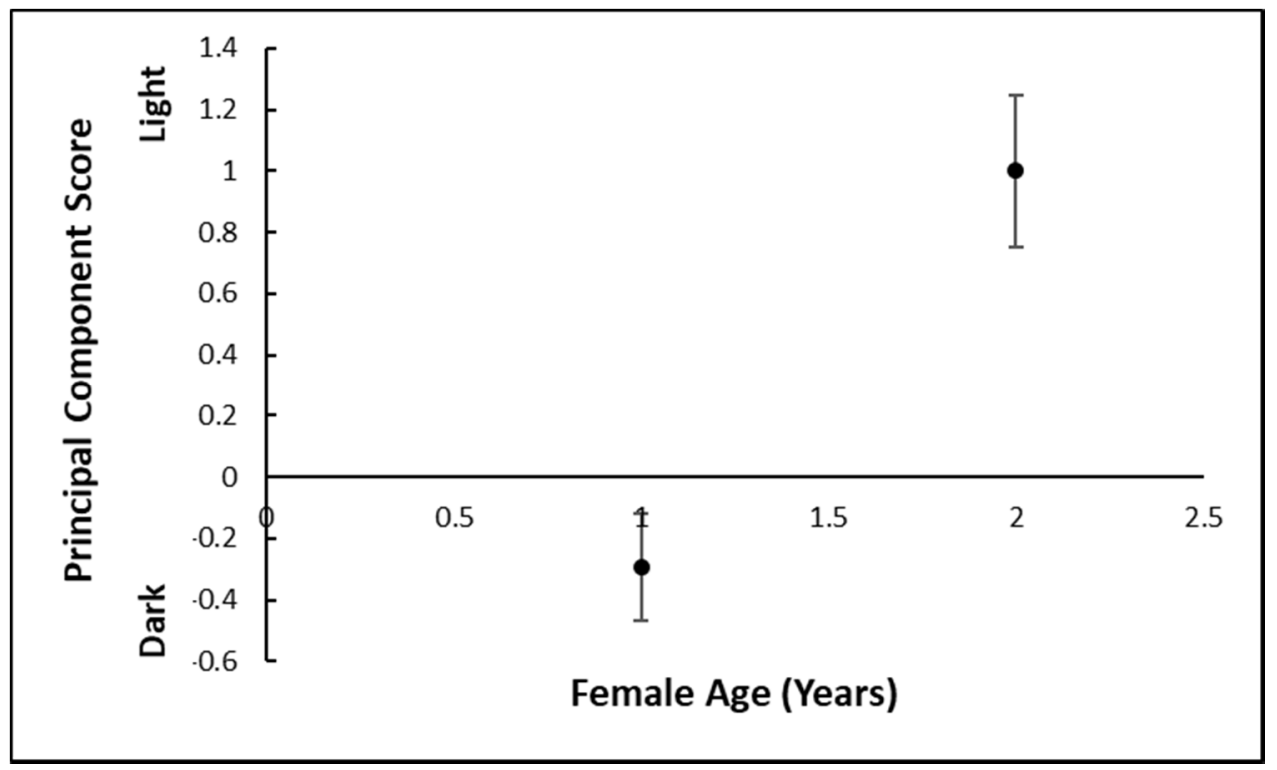

FIGURE A-5. Level of clutch eggshell pigmentation $( \pm \mathrm{SE})$ in relation to female age. Older females laid significantly lighter, less maculated eggs than younger females, who produced more darkly pigmented and densely maculated eggs. 


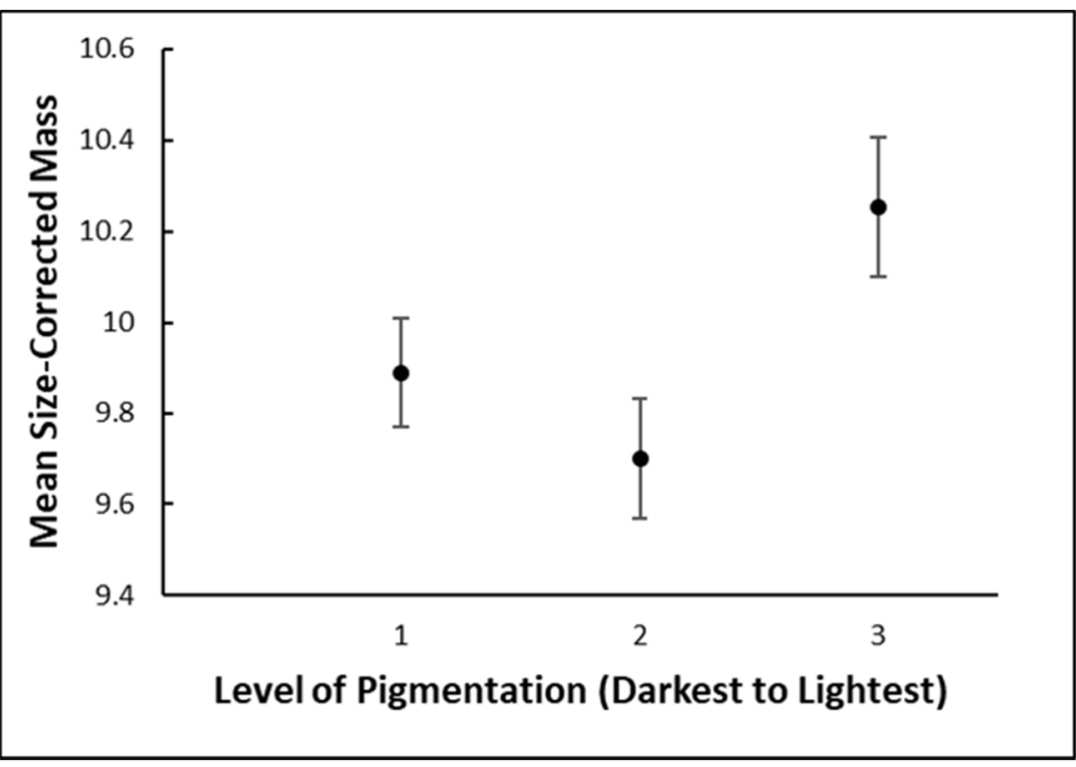

FIGURE A-6. Least-squares nestling size-corrected mass (mass on brood day 11 adjusted for body size, $\pm \mathrm{SE}$ ) in relation to eggshell pigmentation cluster (in which cluster 1 is the darkest category and cluster 3 is the lightest category). 